\title{
New membrane materials for potassium-selective ion-sensitive field-effect transistors
}

\author{
PETER D. VAN DER WAL ", MARIA SKOWRONSKA-PTASINSKA ", ALBERT VAN DEN BERG ${ }^{a, b, c}$, PIET BERGVELD ${ }^{b}$, \\ ERNST J.R. SUDHÖLTER ${ }^{a}{ }^{*}$ and DAVID N. REINHOUDT ${ }^{a *}$ \\ University of Twente, P.O. Box 217, 7500 AE Enschede (The Netherlands)
}

(Received 1st September 1989)

\begin{abstract}
Several polymeric materials were studied as membrane materials for potassium-selective ion-sensitive field-effect transistors (ISFETs) to overcome the problems related with the use of conventional plasticized poly(vinyl chloride) membranes casted on ISFET gate surfaces. Several acrylate materials, such as ACE, Epocryl and derivatives, showed no reproducible results. Three room-temperature vulcanizing (RTV)-type silicone rubbers were tested. The addition-type RTV-2 silicone rubber was not suitable as a membrane material, but the condensation-lype RTV-1 and especially the RTV-2 silicone rubber showed good results. ISFETs with a Silopren membrane showed a durability of at least 2 months.
\end{abstract}

In the last few years there has been increasing interest in the modification of ion-sensitive fieldeffect transistors (ISFETs) with ion-selective membrane materials. Although the most widely used membrane materials are based on plasticized poly(vinyl chloride) (PVC), ISFETs modified with these materials are prone to some serious drawbacks.

The PVC membrane is solvent cast on the encapsulated ISFETs, which means that the preparation of multisensing devices which demands the deposition of different membranes on one set of chips is extremely difficult. Another problem is the durability of the attachment of the membrane to the ISFET surface. The physical interaction between the hydrophilic gate oxide and a hydrophobic polymer (PVC) has been shown to produce

" Laboratory of Organic Chemistry.

b Laboratory of Bio-Informatics.

"Present address: Centre Suisse d'Electronique et de Microtechniquie SA, Rue de la Madalière 71, CH 2007, Neuchâtel, Switzerland. an inferior binding. In addition, membrane components dissolved in a volatile solvent such as tetrahydrofuran (THF) are prone to adsorb moisture from the atmosphere, thus weakening the adhesion between the membrane and the ISFET [1]. Another problem that may arise with the use of thin membrane layers is the leaching out of electroactive components (solvent mediator, ionophore and anionic sites), which may result in an increase in the drift and noise and ultimately in deterioration of the electrode performance.

Several solutions to these problems have been proposed. For instance, a thin polyimide mesh has been suspended over the gate oxide to improve the (mechanical) fastening of the membrane. An increase in the lifetime of the sensor from 2 days to 2 months has been reported [2]. Another method is to avoid a possible contact path between the membrane and the adjacent encapsulant [3]. This was achieved by using a continuous membrane phase over the whole encapsulated device. After the casting of the blank membrane, the electroactive ingredients were introduced by locally doping 
the membrane. It was suggested that this technique could also be used for the preparation of multisensing devices. The lifetime of these sensors was approximately 2 months. Another approach to improving the adhesion of the membrane to the ISFET surface is by chemical modification [4]. Modified PVC containing about $0.6 \mathrm{wt} . \% \mathrm{OH}$ groups can be bound to the hydroxyl groups at the surface of an ISFET by reaction with $\mathrm{SiCl}_{4}$. In addition to this reaction, cross-linking of the PVC chains can also occur. The lifetime of these ISFET sensors was at least 53 days. Also photocross-linking of a plasticizer used in combination with unmodified PVC showed a similar improvement of the lifetime of a sensor based on an $\mathrm{n}$-Si electrode [5]. This indicates that cross-linking contributes to an enhancement of the sensor lifetime.

From the above it is concluded that the PVCbased membranes which perform very well when used in macroelectrodes can only be used with limited success on ISFET sensors after troublesome manipulations and even then several limitations remain. Although several studies have been published on alternative sensing membrane systems, the use of PVC in macro ion-selective electrodes (ISEs) is satisfactory. However, for the use as membrane systems on ISFETs other demands have to be met and it was felt necessary to investigate new polymeric materials for ISFET modification.

Various polymeric materials have been investigated as possible alternatives to PVC. Several polyacrylate systems have been used as matrix materials for calcium ISEs [1,6-8]; some of these were photopolymerized after casting on the gate surface of an ISFET [1], and others after casting on a platinum electrode $[7,8]$. This polyacrylate system has recently been used for a potassium electrode based on a platinum electrode [9]. Poly(vinyl isobutyl ether) has been studied for a calcium and a potassium ISE [10]. For the latter application it was less successful. Polyurethane has been used successfully as a membrane material for a potassium ISE [11]. Negative photoresist has also been used successfully as a membrane material for a potassium-sensitive ISFET [12]. All the investigated membrane materials still need the addition of an external solvent mediator. Examples of solvent mediator-free membranes used for ISEs are silicone rubber [13-15] and a block copolymer of polybisphenol A carbonate and polydimethylsiloxane $[16,17]$.

\section{Molecular design of new ion-selective membrane materials}

Extensive studies on the working mechanism of plasticized PVC-type ISEs with neutral carriers have been reported [18-22]. From these studies, together with studies of alternative membrane systems, some general features of the membrane materials can be abstracted which are of importance in the design of new membrane materials. First, the membrane must be an elastomer and therefore the glass transition temperature must be well below room temperature. For most membrane materials this is accomplished by the addition of large amounts of external solvent mediators. Second, the membrane materials must be hydrophobic in nature, and third, for cation sensitivity anionic sites should be present in the membrane. These can be introduced by the addition of salts of lipophilic anions (e.g., tetraphenylborate). Such salts also lower the electrical membrane resistance. To overcome the problems related to the use of ion-selective membrane systems on ISFETs, previous studies [23-26] have led to the conclusion that the following additional points should be included. The membrane matrix should be covalently bound to the gate oxide surface. In this way the electrode performance does not depend on the poor physical bonding interactions between the hydrophilic surface and the hydrophobic membrane. For compatibility with IC technology, the materials have to be polymerizable or should form cross-links on radiation with UV light. On the device level this also might contribute to the development of multisensing devices. Finally, to improve the lifetime and to avoid problems related to the leakage of membrane materials, covalent binding of all membrane components should be considered. These include the plasticizing groups, anionic sites and the ionophore.

In this paper an exploratory study on acrylateand siloxane-based membrane materials for ISFET modification is described. The acrylate systems are of interest since they can be photopolymerized 
<smiles>COc1c(COCCOCCOCCOCc2cc(C)cc(-c3cc(C)cc(-c4cc(C)cc(C)c4C)c3C)c2C)cc(C)cc1C(=O)OC(C)C(=O)OC(C(=O)NC(C(=O)OCC1CC1)C(=O)OC(C(C)C)C(C)C)C(C)C</smiles><smiles>COc1ccc(C)cc1COc1ccccc1OCCOc1ccccc1OCc1cc(C)cc(-c2cc(C)cc(-c3cc(C)cc(-c4cc(C)cc(C)c4O)c3C)c2C)c1C</smiles><smiles>COc1ccc(C)cc1COCCOc1ccc(CO)cc1OCCOCc1cc(C)cc(-c2cc(C)cc(-c3cc(C)cc(C)c3OC)c2I)c1C</smiles>

3

Fig. 1. Structural formulae of the investigated neutral ionophores.

and photocross-linked to the ISFET gate oxide. The siloxanes are promising materials because of their intrinsic plastic properties and hydrophobic nature. These materials were investigated for their properties in relation to the development of a potassium-selective ISFET sensor based on neutral ionophores of natural and synthetic origin. The aspect of covalent binding of the ionophore and anionic sites to the membrane system is not part of this study. The neutral ionophores used in this study are valinomycin (1), hemispherand-21 (2), diphenylhemispherand-21 (3) and hydroxy- methyl phenyl hemispherand-21 (4), the structures of which are shown in Fig. 1.

\section{EXPERIMENTAL}

\section{ISFETS}

The ISFETs used in this work have a $\mathrm{SiO}_{2}$ gate oxide, which was thermally grown in an oxygen atmosphere for $10 \mathrm{~min}$ at $1150^{\circ} \mathrm{C}$ (thickness $\approx 700$ $\AA$ ). They were mounted on a printed circuit board, wire bonded and encapsulated with epoxy resin 
(Hysol). The ISFETs were measured in a constant drain-current mode $\left(I_{\mathrm{d}}=100 \mu \mathrm{A}\right)$, with a constant drain-source potential $\left(V_{\mathrm{ds}}=0.5 \mathrm{~V}\right)$. A saturated calomel electrode was used as a reference electrode with a double junction containing $0.1 \mathrm{M}$ $\mathrm{NaCl}$. A potassium ion-selective electrode (Ingold 152213000 ) was used to measure the potassium activity and was calibrated before use.

\section{Chemicals}

Di-n-butyl phthalate (DBP) was purchased from $\mathrm{BDH}$. Octan-1-ol, valinomycin and potassium tetrakis(4-chlorophenyl)borate $\left[\mathrm{KB}(\phi \mathrm{Cl})_{4}\right]$ were obtained from Fluka. Potassium dinonylnaphthalene sulphonate (K-DNNS) was prepared by neutralizing the corresponding acid (Polysciences) with potassium carbonate. The alkali metal salts used were of analytical-reagent grade (Merck-Schuchardt), except sodium chloride (Suprapur).

The structural formulae of the investigated synthetic ionophores are shown in Fig. 1. The synthesis of the hemispherands 2 [27] and 3 [28] has been described elsewhere.

\section{Synthesis of hemispherand 4}

First the corresponding aldehyde was synthesized. A solution of $1.65 \mathrm{~g}(3 \mathrm{mmol})$ of $3,3^{\prime}$ bis(bromomethyl)-2,2',2'-trimethoxy-1, $1^{\prime}: 3^{\prime}, 1^{\prime \prime}$ terphenyl and $0.69 \mathrm{~g}(3.05 \mathrm{mmol})$ of 4-formyl-1,2bis(2-hydroxyethoxy)benzene in $40 \mathrm{ml}$ of dry THF was added during $16 \mathrm{~h}$ to a refluxing suspension of $0.3 \mathrm{~g}(0.0125 \mathrm{mmol})$ of $\mathrm{NaH}$ in $400 \mathrm{ml}$ of dry THF. The mixture was cooled to room temperature and the excess of $\mathrm{NaH}$ was reacted with $5 \mathrm{ml}$ of water. The solvent was evaporated and the remaining residue was solubilized in dichloromethane and water. The aqueous layer was acidified to $\mathrm{pH} 2$ using $4 \mathrm{M} \mathrm{HCl}$. The layers were separated and the organic layer was dried $\left(\mathrm{MgSO}_{4}\right)$. After filtration and evaporation of the solvent, the material was purified by column chromatography on alumina with THF-dichloromethane $(5+95, \mathrm{v} / \mathrm{v})$ as eluent. Yield, $700 \mathrm{mg}$ $(38 \%)$; mass spectrum, $m / z=612,2767 \quad\left(\mathrm{M}^{+}\right.$; calculated for $\mathrm{C}_{37} \mathrm{H}_{40} \mathrm{O}_{8}, 612.2723$ ).

The hydroxy compound 4 was synthesized by reduction of the aldehyde with $\mathrm{NaBH}_{4}$. The aldehyde hemispherand, $0.40 \mathrm{~g}(0.66 \mathrm{mmol})$, and
$0.05 \mathrm{~g}(1.2 \mathrm{mmol})$ of $\mathrm{NaBH}_{4}$ in $20 \mathrm{ml}$ of methanol were stirred for $2 \mathrm{~h}$ at room temperature. The excess of $\mathrm{NaBH}_{4}$ was reacted with water. After neutralization with $\mathrm{HCl}$ the solvent was evaporated and the remaining residue was solubilized in chloroform and water. The layers were separated and the organic layer was dried $\left(\mathrm{MgSO}_{4}\right)$. After filtration and evaporation of the solvent the material was purified by column chromatography on alumina with ethyl acetate-chloroform $(25+75$, $v / v$ ) as eluent and subsequently by recrystallization from ethanol. The ${ }^{1} \mathrm{H}$ NMR spectra, recorded in $\mathrm{CDCl}_{3}$, indicate the presence of two forms of the hemispherand in a ratio of approximately $5: 1$. Yield, $150 \mathrm{mg}$ (50\%); m.p., 234-235 ${ }^{\circ} \mathrm{C}$; ' $\mathrm{H}$ NMR, $\delta$ 7.20-7.05 (m, 6H, ArH), 6.85-6.60 (m, 3H, ArH) $4.82\left(\mathrm{AB}, J_{\mathrm{AB}}=10.5 \mathrm{~Hz}, 2 \mathrm{H}, \mathrm{ArCH}_{2}\right.$, minor), $4.76\left(\mathrm{AB}, J_{\mathrm{AB}}=10.5 \mathrm{~Hz}, 2 \mathrm{H}, \mathrm{ArCH}_{2}\right.$, major), 4.53 (bs, $\left.2 \mathrm{H}, \mathrm{ArCH}_{2} \mathrm{OH}\right), 4.44\left(\mathrm{AB}, J_{\mathrm{AB}}=\right.$ $10.5 \mathrm{~Hz}, 2 \mathrm{H}, \mathrm{ArCH}_{2}$, minor $), 4.40\left(\mathrm{AB}, J_{\mathrm{AB}}=10.5\right.$ $\mathrm{Hz}, 2 \mathrm{H}, \mathrm{ArCH}_{2}$, major), 4.20-3.50 (m, 8H, $\left.\mathrm{OCH}_{2}\right), 3.74$ and $3.71\left(\mathrm{~s}, 6 \mathrm{H}\right.$, outer $\mathrm{OCH}_{3}$, major), $3.33\left(\mathrm{~s}, 6 \mathrm{H}\right.$, outer $\mathrm{OCH}_{3}$, minor $), 3.28(\mathrm{~s}, 3 \mathrm{H}$, inner $\mathrm{OCH}_{3}$, minor), $2.84\left(\mathrm{~s}, 3 \mathrm{H}\right.$, inner $\mathrm{OCH}_{3}$, major), $2.39\left(\mathrm{~s}, 3 \mathrm{H}\right.$, inner $\left.\mathrm{CH}_{3}\right), 2.33(\mathrm{~s}, 6 \mathrm{H}$, outer $\left.\mathrm{CH}_{3}\right)$; IR (KBr), $3450 \mathrm{~cm}^{-1}(\mathrm{OH})$; mass spectrum, $m / z \quad 614.2875 \quad\left(\mathrm{M}^{+}\right.$; calculated for $\mathrm{C}_{37} \mathrm{H}_{42} \mathrm{O}_{8}, 614.2879$ ).

\section{Acrylates}

The photoinitiator used was 2,2-dimethoxy-2phenylacetophenone (Janssen Chimica). The acrylates Epocryl DRH 370 and ACE were gift samples from Shell (Amsterdam). ACE is produced from methacrylic acid and Cardura (Scheme 1).

Analysis showed that the batch contained a high number of acidic groups $(4.2 \mathrm{mg}$ of $\mathrm{KOH}$ was needed to neutralize $1 \mathrm{~g}$ of $\mathrm{ACE}$; this corresponds to an acid number of $0.075 \mathrm{meq}^{-1}$ ). To reduce the acid number, the following reactions were performed with ACE. (a) Reaction with diazomethane (ACE: $\mathrm{CH}_{2} \mathrm{~N}_{2}=1: 10$ ). Alter his reaction, the acid number decreased to $2.5 \mathrm{mg} \mathrm{KOH}$ $\mathrm{g}^{-1}\left(=0.045 \mathrm{meq}^{-1}\right)$. Reaction with Cardura. (b) $A C E$ and Cardura were mixed in a $1: 1$ ratio and heated at $115^{\circ} \mathrm{C}$ for $4 \mathrm{~h}$. The acid number of the final product was $\leqslant 0.01 \mathrm{mg} \mathrm{KOH} \mathrm{g}^{-1}(\leqslant 0.00018$ 

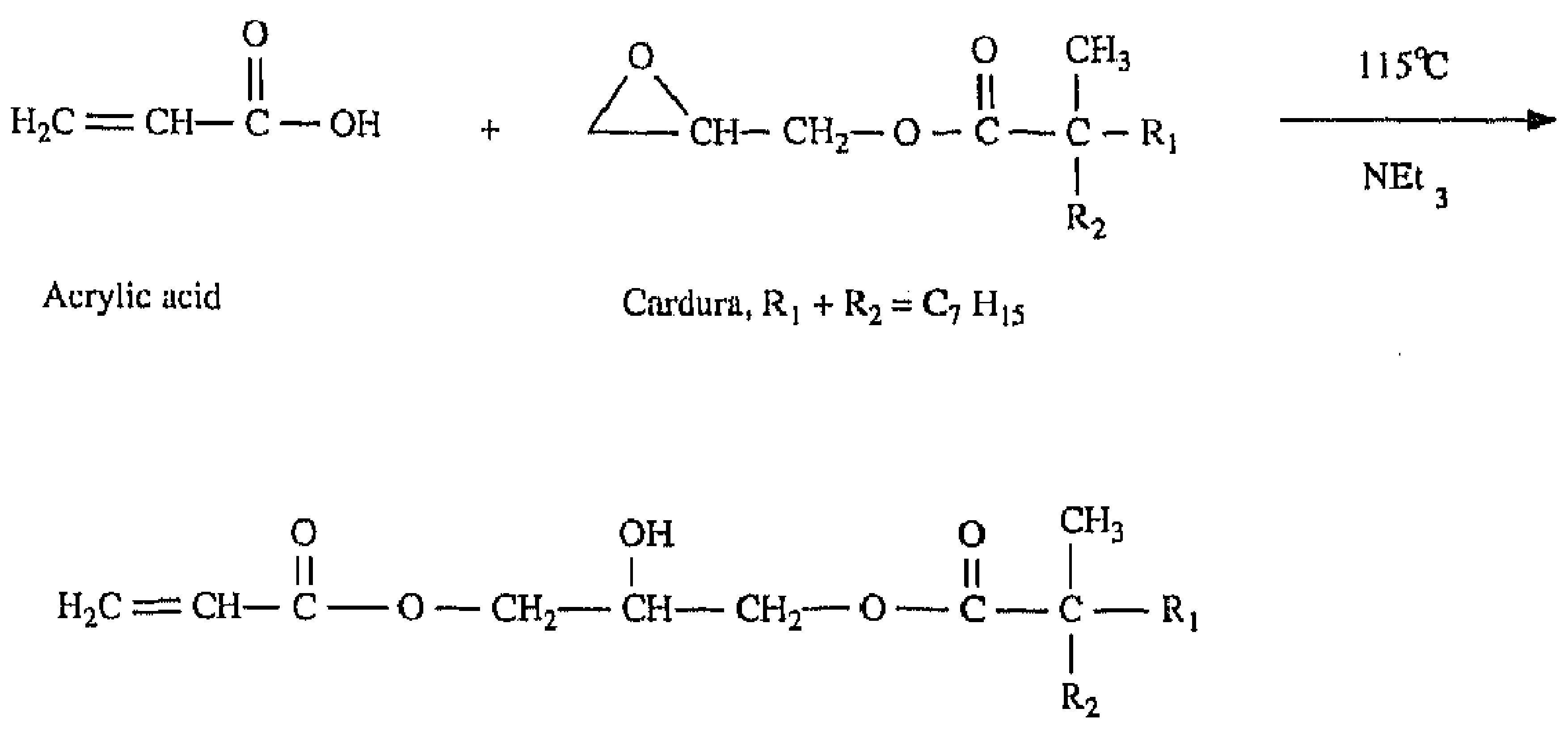

ACE<smiles>C=C(C)C(=O)OCC(O)CCOc1ccc(C(C)(C)c2ccc(OCC(O)CC(C)C)cc2)cc1</smiles>

Epocryl DRH $370(n=1.2)$

Scheme 1. Structural formulae of Cardura, ACE, and Epocryl DRH 370.

meq $\mathrm{g}^{-1}$ ). (c) ACE and Cardura were mixed in a $1: 2$ ratio and heated at $115^{\circ} \mathrm{C}$ for $4 \mathrm{~h}$. The acid number of the product had decreased to $0.11 \mathrm{mg}$ $\mathrm{KOH} \mathrm{g}^{-1}\left(=0.002 \mathrm{meq} \mathrm{g}^{-1}\right)$. (d) ACE was heated at $115^{\circ} \mathrm{C}$ for $1 \mathrm{~h}$. After this heat treatment the acid number had decreased to $0.1 \mathrm{mg} \mathrm{KOH} \mathrm{g}^{-1}$ $\left(=0.0018 \mathrm{meq} \mathrm{g}^{-1}\right)$.

As can be seen from experiment (d), heating of ACE alone is sufficient to reduce the acid number considerably. From this it may be concluded that ACE as received still contains some unreacted acid and epoxy groups. After treatment (a), attempts to photopolymerize the ACE failed. ACE possesses a free $\mathrm{ROH}$ group, which has been used for subsequent chemical modification (Scheme 2).

(e) Reaction of ACE with $\epsilon$-caprolactone. A $1: 1(\mathrm{w} / \mathrm{w})$ mixture of ACE and e-caprolactone with a catalytic amount of di-n-butyltin dilaurate was stirred for $4 \mathrm{~h}$ at $140^{\circ} \mathrm{C}$. During the reaction air was bubbled through the mixture to prevent the polymerization reaction. (f) Reaction of $\mathrm{ACE}$ with acid chloride. A $1: 1(\mathrm{w} / \mathrm{w})$ mixture of $\mathrm{ACE}$ and acetyl chloride or pentanoyl chloride was stirred for $1 \mathrm{~h}$ at room temperature and additionally for $1 \mathrm{~h}$ at $50^{\circ} \mathrm{C}$. (g) $\mathrm{ACE}$, modified by reaction (e) with $\epsilon$-caprolactone, was subsequently reacted with pentanoyl chloride by stirring for $1 \mathrm{~h}$ at room temperature and subsequently for $1 \mathrm{~h}$ at $50^{\circ} \mathrm{C}$.

To ensure thermodynamically well defined solid-membrane interfaces [29,30], all ISFETs modified with the different acrylate membranes contained an intermediate hydrogel layer of poly(2hydroxyethyl methacrylate) (polyHEMA) between the ISFET surface and the sensing membrane. The hydrogel is conditioned in $0.1 \mathrm{M} \mathrm{KCl}$.

The different acrylate monomers mixed with 4 wt.-\% of 2,2-dimethoxy-2-phenylacetophenone photoinitiator were dissolved in THF (100 mg $\mathrm{ml}^{-1}$ ) and solvent cast on the gate surface of an encapsulated ISFET. The ISFETs were left for 30 min at room temperature in order to evaporate the solvent, then the ISFETs were photocured in a nitrogen-purged quartz tube under a high-intensity, medium-pressure mercury vapour lamp (Philips HPK $125 \mathrm{~W}$ ) at a distance of $6-8 \mathrm{~cm}$ from the lamp. Most of the neat acrylate membranes were polymerized completely in less than 2 min. Membranes containing external plasticizer needed a longer curing time of about $10 \mathrm{~min}$. 


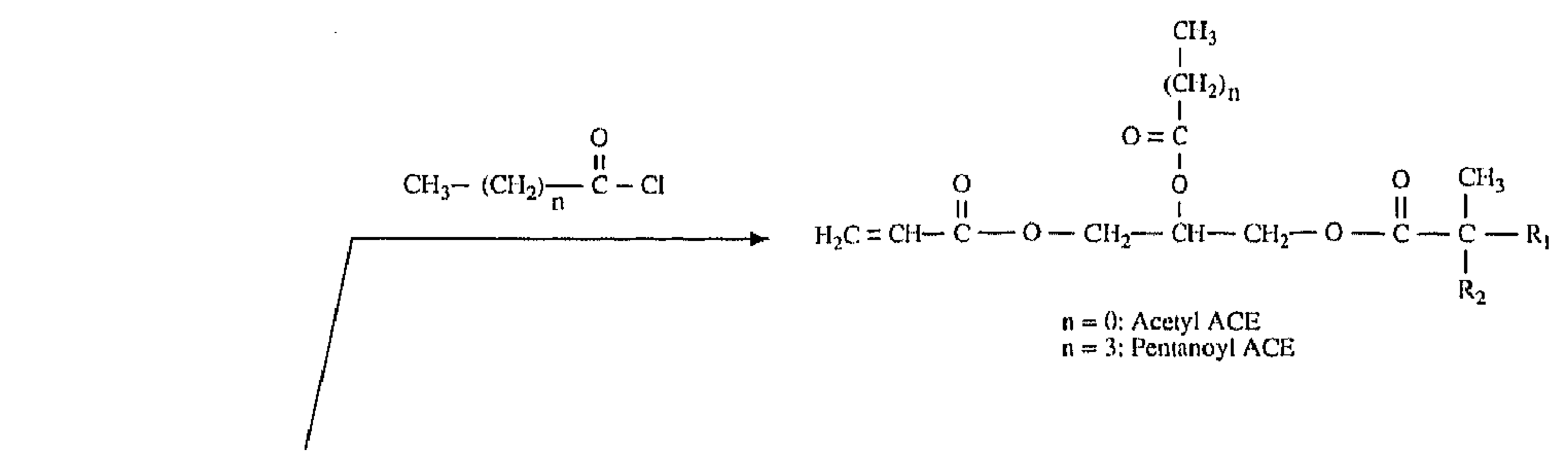

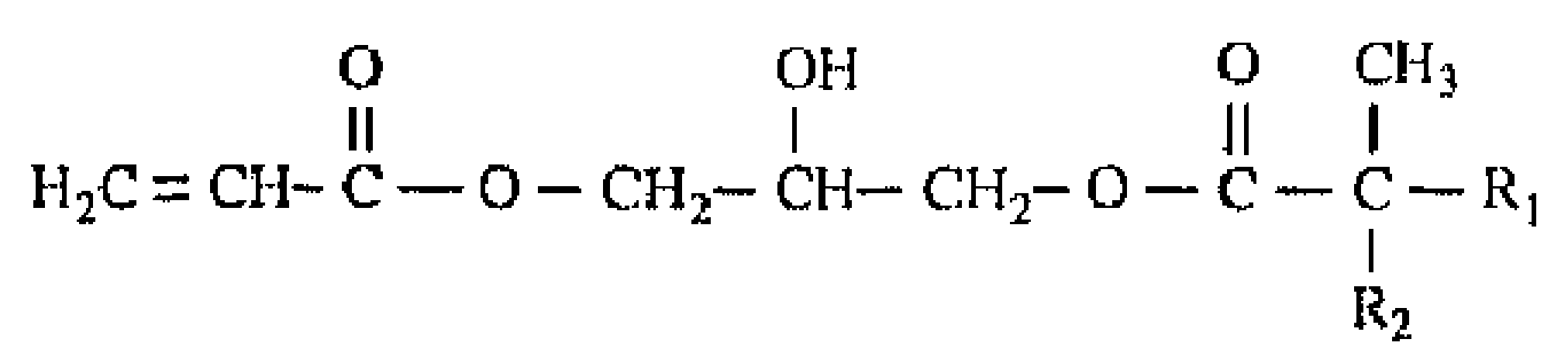

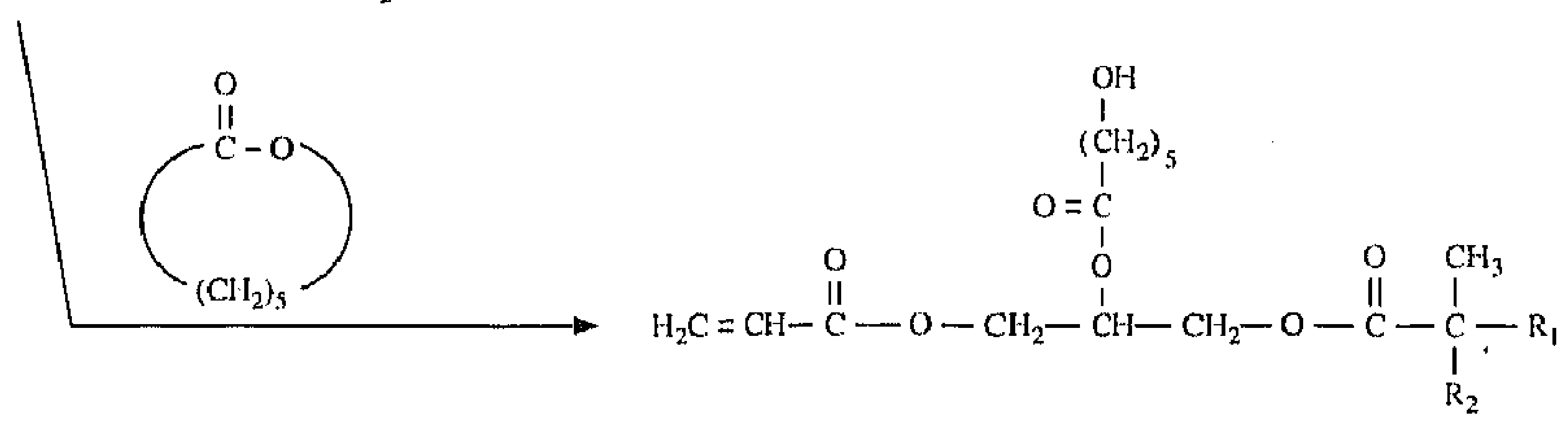

Hydroxyhexintoyl ACE

$\mathrm{H}_{3} \mathrm{C}-\left(\mathrm{CH}_{2}\right)_{3}-\stackrel{O}{\mathrm{C}}-\mathrm{Cl}$<smiles>[R]C([R])(C)C(=O)OCC(COC(=O)C=C)OC(=O)COC(=O)CC</smiles>

Pentanoic acid ester of hydroxyhexanoyl ACE

Scheme 2. Chemical modification of ACE monomer.

\section{Polysiloxanes}

Three commercially available room-temperature vulcanizing (RTV)-type silicone rubbers were tested for their properties as membrane materials.

Silopren (Bayer, Leverkusen) is a two-component room-temperature vulcanizing (RTV-2)-type silicone rubber. A $50-\mathrm{mg}$ amount of Silopren $\mathrm{K} 1000$ and $3-5 \mathrm{wt} . \%$ of the ionophore were dis- solved in $1 \mathrm{ml}$ of dichloromethane, then $5 \mathrm{mg}$ of cross-linking agent (Silopren Vernetzer KA-1), dissolved in $0.5 \mathrm{ml}$ of dichloromethane, were added. The solutions were mixed thoroughly and one drop was transferred to the gate surface of an encapsulated ISFET. The membrane cured at room temperature in 30-60 min.

RTV ME-625 (Wacker) is also an RTV-2-type 
silicone rubber. A $150-\mathrm{mg}$ amount of component $A$ and an amount of the ionophore were dissolved in $1 \mathrm{ml}$ of dichloromethane and mixed with 15-20 $\mathrm{mg}$ of component $\mathrm{B}$, dissolved in $0.35 \mathrm{ml}$ of dichloromethane. A drop of this solution was transferred to the gate surface of an encapsulated ISFET. After evaporation of the solvent the silicone rubber was cured at room temperature for 15 h. At elevated temperature the reaction rate was accelerated considerably; at $80^{\circ} \mathrm{C}$ the silicone rubber was cured in $20 \mathrm{~min}$. However, the curing reaction was sometimes inhibited by the addition of the ionophore: using $4 \mathrm{wt} . \%$ of valinomycin, the silicone rubber failed to cure. In the presence of 0.9 wt.-\% of ionophore, no reaction inhibition was observed.

3140 RTV (Dow Corning) is an RTV-1-type silicone rubber. A 50-mg amount of 3140 RTV and $3 \mathrm{wt} . \%$ of ionophore were dissolved in $1 \mathrm{ml}$ of dichloromethane. A drop of this solution was transferred to the gate surface of an encapsulated ISFET. The membrane cured in air in at least 24 h.

\section{RESULTS AND DISCUSSION}

\section{Acrylate- and methacrylate-based membranes}

In an earlier study [31,32] it was found that the commercial acrylic ester ACE and the methacrylic ester Epocryl DRH 370 perform very well as membrane materials in the preparation of reference FETs (REFETs). In this study experiments on the preparation of potassium-selective ISFETs with these materials are reported.
ACE is manufactured from acrylic acid and Cardura and Epocryl DRH 370 from bisphenol A, epichlorohydrin and methacrylic acid (Scheme 1). Epocryl is a mixture of monomers with predominantly $n=1$ and 2 (average $n=1.2$ ). These monomers are of special interest since they can be polymerized and cross-linked by photolithographic procedures. It was found necessary to apply an interlayer of polyHEMA between the silylated gate oxide and the (meth)acrylate polymer system in order to make the modified ISFETs adjustable, and to reduce electrical noise originating from the thermodynamically ill-defined interface of the (meth)acrylate polymer system and the gate oxide $[29,30]$. Also in this study the (meth) acrylates were deposited and photopolymerized on polyHEMA-modified ISFETs (see Experimental). The modified ISFET is shown schematically in Fig. 2.

If ACE is photopolymerized, a soft, slightly brittle polymer is formed. Although no quantitative measurements of the glass transition temperature, $T_{\mathrm{g}}$, have been done, from visual and mechanical inspection we observed that the $T_{\mathrm{g}}$ of polymerized $\mathrm{ACE}$ is well below room temperature. In the absence of an ionophore, a cation response of $44 \mathrm{mV}$ decade $^{-1}$ was observed as a function of the potassium ion concentration in the analyte solution. It was concluded that anionic groups must be present in the membrane. Titration of the $\mathrm{ACE}$ monomer with standard $\mathrm{KOH}$ solution indicated the presence of acidic groups (presumably unreacted acrylic acid). The acid number $(A N)$ is $4.2 \mathrm{mg} \mathrm{KOH} \mathrm{g}{ }^{-1}$, which corresponds to $75 \times 10^{-6}$

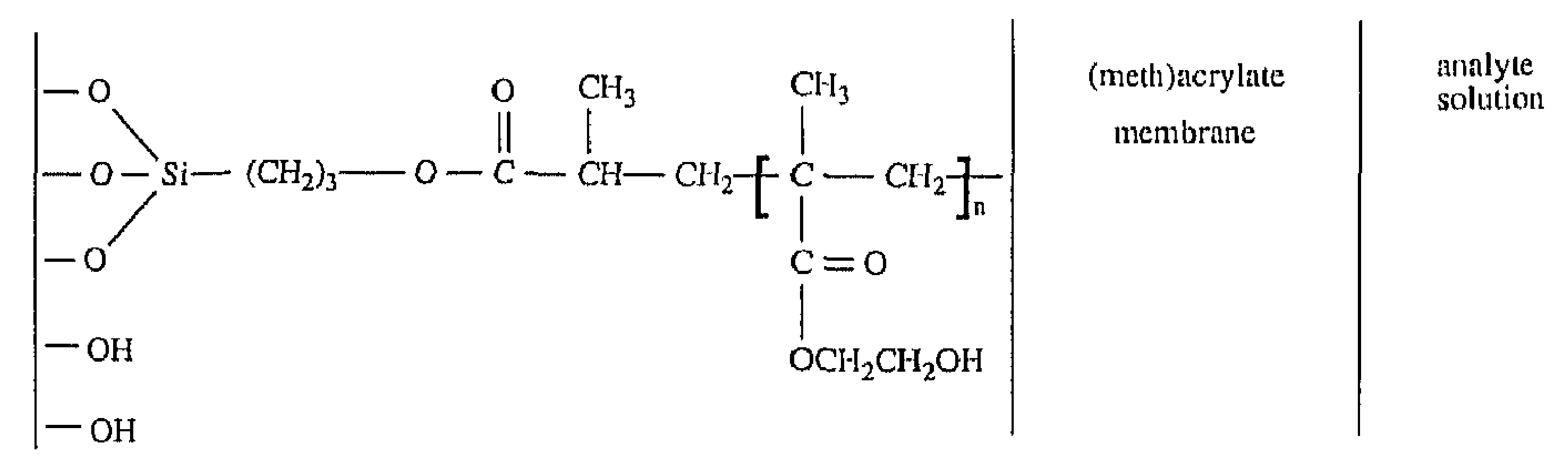

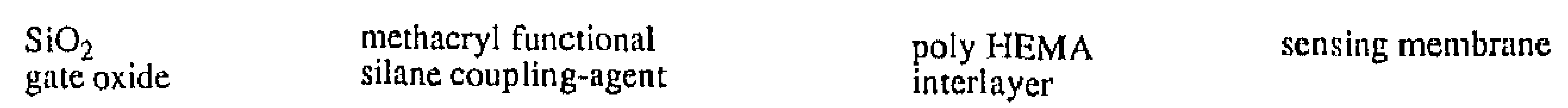

Fig. 2. Schematic representation of the chemically modified ISFET used. 
eq acid $\mathrm{g}^{-1}$ ACE monomer. Addition of valinomycin ionophore to ACE monomer followed by photopolymerization did not result in cation (potassium) selectivity. This means that although a potassium permselectivity of about $44 \mathrm{mV}$ decade $^{-1}$ is observed, in the presence of $0.1 \mathrm{M} \mathrm{NaCl}$ or $\mathrm{LiCl}$ the sensitivity for the detection of potassium is completely lost. This prompted the investi-

TABLE 1

Effect of polymeric membrane composition on the potassium sensitivity of chemically modified ISFETS

(A) Effect of ACE to Epocryl ratio:

\begin{tabular}{|c|c|c|c|}
\hline $\begin{array}{l}\text { ACE: Epocryl } \\
(w / w)\end{array}$ & $\begin{array}{l}\text { Plasticizer } \\
\left(w t_{-}-\%\right)\end{array}$ & $\begin{array}{l}\text { Ionophore } \\
\text { (wt..\%) }\end{array}$ & $\begin{array}{l}\mathrm{K}^{+} \text {sensitivity } \\
\left(\mathrm{mV} \text { decade }{ }^{-1}\right)\end{array}$ \\
\hline$\overline{1: 0}$ & $\mathrm{DBP}^{\mathrm{b}}(50)$ & $1(2)$ & $48^{c}$ \\
\hline $0.50: 0.50$ & $\mathrm{DBP}^{\mathrm{b}}(67)$ & $1(2)$ & $36^{\circ}$ \\
\hline $0: 1$ & $\mathrm{DBP}^{b}(67)$ & $2(2)$ & $45^{\mathrm{d}}$ \\
\hline
\end{tabular}

(B) Effect of external plasticizer:

\begin{tabular}{|c|c|c|c|}
\hline Monomer & $\begin{array}{l}\text { Plasticizer } \\
\text { (wt.-\%) }\end{array}$ & $\begin{array}{l}\text { Ionophore } \\
\text { (wt.-\%) }\end{array}$ & $\begin{array}{l}\mathrm{K}^{+} \text {sensitivity } \\
\left(\mathrm{mV} \text { decade }^{-1}\right)\end{array}$ \\
\hline$\overline{\mathrm{ACE}}$ & $\mathrm{DBP}^{\mathrm{b}}(50)$ & $2(2)$ & $48^{c}$ \\
\hline $\mathrm{ACE}$ & $\mathrm{DBP}^{\mathrm{b}}(67)$ & $1(5)$ & $50^{\prime \prime}$ \\
\hline $\mathrm{ACE}$ & Oct $^{e}(50)$ & $1(5)$ & $54^{\mathrm{d}}$ \\
\hline $\mathrm{ACE}$ & Oct $^{\mathbf{c}}(75)$ & $1(5)$ & $50^{d}$ \\
\hline
\end{tabular}

(C) Effect of covalently bound plasticizer:

\begin{tabular}{|c|c|c|}
\hline Monomer ${ }^{\top}$ & $\begin{array}{l}\text { Ionophore } \\
\text { (wt.-\%) }\end{array}$ & $\left.\begin{array}{l}\mathrm{K}^{+} \text {sensitivity } \\
(\mathrm{mV} \text { decade } \\
-1\end{array}\right)$ \\
\hline Hydroxyhexanoyl ACE & $1(3)$ & $45^{\mathrm{d}}$ \\
\hline Acetyl ACE & $1(3)$ & $45^{\mathrm{d}}$ \\
\hline Pentanoyl ACE & $1(3)$ & $45^{\mathrm{d}}$ \\
\hline Pentanoic acid ester of hydroxyhexanoyl ACE & $1(3)$ & $50^{c}$ \\
\hline
\end{tabular}

(D) Effect of acid number $(A N)$ :

\begin{tabular}{|c|c|c|c|}
\hline Monomer ${ }^{a}$ & $A N \mathrm{~B}$ & $\begin{array}{l}\text { Ionophore } \\
(\mathrm{wt.}-\%)\end{array}$ & $\begin{array}{l}\mathrm{K}^{+} \text {sensitivity } \\
\left(\mathrm{mV} \text { decade }{ }^{-1}\right)\end{array}$ \\
\hline$\widehat{\mathrm{ACE}}$ & 4.2 & $1(3)$ & $44^{1}$ \\
\hline $\mathrm{ACE}+$ Cardura $(1: 2, w / w)$ & 0.11 & $1(2)$ & $33^{\mathrm{d}}$ \\
\hline ACE (heat treated) & 0.1 & $1(2)$ & $33 d$ \\
\hline $\mathrm{ACE}+\operatorname{Cardura}(1: 1, w / w)$ & 0.01 & $1(2)$ & $33^{4}$ \\
\hline \multicolumn{4}{|l|}{ (E) Effect of lipophilic salts: } \\
\hline Monomer ${ }^{a, i}$ & Lipophilic salt & $\begin{array}{l}\text { Ionophore } \\
\text { (wt.-\%) }\end{array}$ & $\begin{array}{l}\mathrm{K}^{+} \text {sensitivity } \\
\left(\mathrm{mV} \text { decade }{ }^{-1}\right)\end{array}$ \\
\hline$\overline{\mathrm{ACE}}$ & $\mathrm{KB}(\phi \mathrm{Cl})_{4}^{\mathrm{h}}$ & $1(3)$ & $44^{\mathrm{d}}$ \\
\hline $\mathrm{ACE}+$ Cardura $(1: 1, w / w)$ & KDNNS ${ }^{i}$ & $1(2)$ & $45^{d}$ \\
\hline$A C E+$ Cardura $(1: 2, w / w)$ & KDNNS ${ }^{i}$ & $1(2)$ & $45^{d}$ \\
\hline $\mathrm{ACE}+\mathrm{CH}_{3} \mathrm{COCl}(1: 1, w / w)$ & $\mathrm{KB}(\phi \mathrm{Cl})_{4}^{h}$ & $1(3)$ & $47 d$ \\
\hline $\mathrm{ACE}+\mathrm{n}-\mathrm{C}_{4} \mathrm{H}_{9} \mathrm{COCl}(1 ; 1, \mathrm{w} / \mathrm{w})$ & $\mathrm{KB}(\phi \mathrm{Cl})_{4}^{\mathrm{h}}$ & $1(3)$ & $48^{d}$ \\
\hline $\mathrm{ACE}+$-caprolactone $+\mathrm{n}-\mathrm{C}_{4} \mathrm{H}_{9} \mathrm{COC}$ & $\mathrm{KB}(\phi \mathrm{Cl})_{4}^{h}$ & & \\
\hline$(1: 1: 1, w / w / w)$ & & $1(2)$ & $45^{\prime \prime}$ \\
\hline
\end{tabular}

"See Scheme 1. "DBP = di-n-butyl phthalate. " $0.1 \mathrm{M} \mathrm{LiCl}$ background electrolyte. "No background electrolyte. "Oct $=$ octan-1ol. "See Scheme 2. ${ }^{\mathrm{g}} A N=$ acid number, mg KOH g-1 polymer. " Potassium tetrakis(4-chlorophenyl)borate, $0.95 \times$ ionophore concentration. 'Potassium dinonylnaphthalene sulphonate, $0.044 \times$ ionophore concentration. 
gation of the polymer system in more detail and the composition was varied by changing the ACE to Epocryl monomer ratio, the type of external plasticizer (di-n-butyl phthalate and octan-1-ol), the acid number and the addition of the lipophilic salts potassium tetrakis(4-chlorophenyl)borate and potassium dinonylnaphthalene sulphonate. It was disappointing that, despite all the variations made, only occasionally could potassium selectivity be observed. The potassium selectivity of these devices was irreproducible and vanished after the devices had been exposed to the electrolyte overnight. In Table 1 some typical membrane compositions are shown in combination with the observed potassium sensitivity in the absence of an interfering electrolyte.

The ACE monomer was also modified (Scheme 2) by reaction of the hydroxyl group. In this way acetyl, pentanoyl and hydroxyhexanoyl ACE were synthesized and also the pentanoic acid ester of the latter compound. Polymers of these modified ACE monomers prepared on ISFET devices showed a sub-Nernstian potassium sensitivity of $45 \mathrm{mV}$ decade $^{-1}$ (Table 1, C). No potassium selectivity could be observed for these membranes.

\section{Polysiloxane-based membranes}

Three different types of commercially available and RTV siloxanes were investigated, viz., the addition type Wacker RTV-ME 625 and the condensation types Dow Corning 3140 RTV and Silopren (Bayer) (Scheme 3). These siloxanes form polymeric membranes by addition or polycondensation reaction. In contrast to the (meth)acrylate membranes, it was not necessary to introduce a polyHEMA interlayer in order to obtain adjustable modified ISFETs. Although the presence of such a layer has shown a positive effect on the reduction of noise on the output signal and also eliminates interference from carbon dioxide
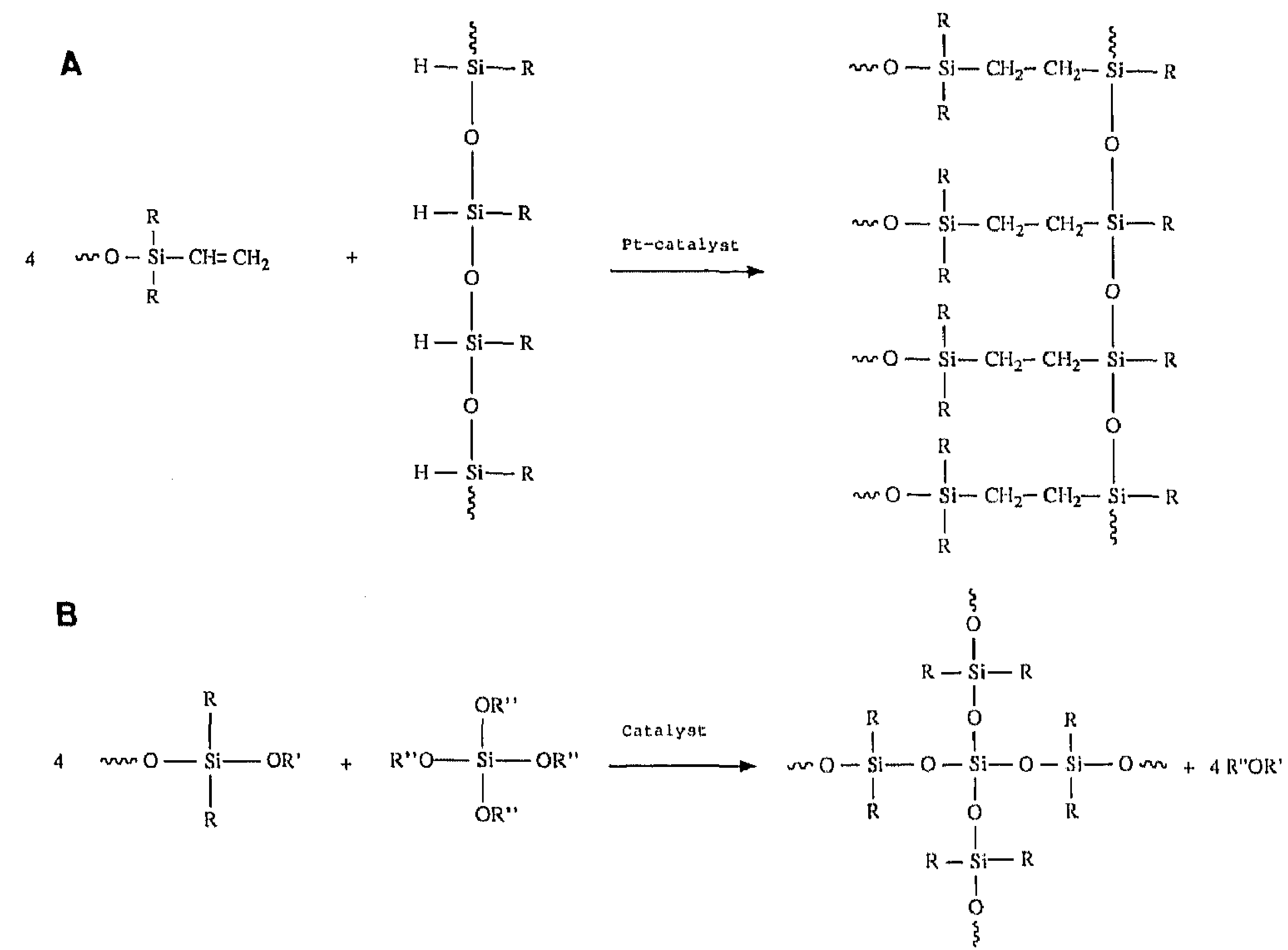

Scheme 3. Idealized reaction scheme of the investigated polysiloxanes. (A) Addition type cure reaction; Wacker RTV ME 625, $\mathrm{R}=$ methyl. (B) Condensation-type cure reaction. (i) Dow Corning $3140 \mathrm{RTV}, \mathrm{R}=\mathrm{R}^{\prime}=\mathrm{R}^{\prime \prime}=$ methyl; water from the air and a titanium catalyst are needed. (ii) Bayer Silopren, $R=$ methyl, $R^{\prime}=H, R^{\prime \prime}=$ ethyl; an organotin catalyst is used. 
$[29,30]$, in this study the polysiloxane membranes are in direct contact with the gate oxide. The Wacker RTV-ME 625 material is a two-component (RTV-2) addition-type silicone rubber. The cure reaction involves the addition of $\mathrm{SiH}$ groups to vinyl groups. A platinum catalyst facilitates this reaction. However, in the presence of $4 \mathrm{wt} .-\%$ of valinomycin the hydrosilylation reaction was inhibited. The addition of less valinomycin $(<1$ wt.-\%) did not inhibit the curing reaction. This suggests that there is some kind of interaction between the ionophore and the catalyst. ISFETs modified with these membranes showed irreproducible results, probably owing to the absence of sufficient amounts of free valinomycin.

Dow Corning 3140 RTV is an RTV-1 type of silicone rubber. With uptake of moisture from the atmosphere and the action of a titanium catalyst, polycondensation of the methoxy terminated polysiloxanes and a multifunctional silane takes place. During this condensation reaction methanol is liberated. The material has been used previously in the preparation of a conventional ion-selective electrode [33]. Using this material and valinomycin for the modification of ISFETs, a good performance of the potassium-selective sensor was observed, in both the absence and presence of the lipophilic salt potassium tetrakis(4-chlorophenyl)borate (Table 2). The response as a function of the potassium ion concentration has a nearly Nernstian slope of $56 \mathrm{mV}\left(\mathrm{pK}^{+}\right)^{-1}$ over the entire measured concentration range (Fig. 3 ).

The lifetime of the sensor was about 2 weeks and could be increased to at least 4 weeks by the incorporation of the lipophilic salt. In both cases the modified ISFETs were immersed continuously in the analyte solution. It is possible that the lifetime is limited by leaching of anionic sites from the membrane phase. The membrane shows very good adhesion to the gate oxide. Since the curing reaction also involves the reaction of silanol groups, the silicone rubber probably covalently binds to the ISFET surface.

The Bayer Silopren material is also an RTV-2 type of silicone rubber, containing silanolterminated polysiloxane and tetraethoxysilane. By the action of an organotin catalyst, polycondensation takes place. The use of Silopren in neutral

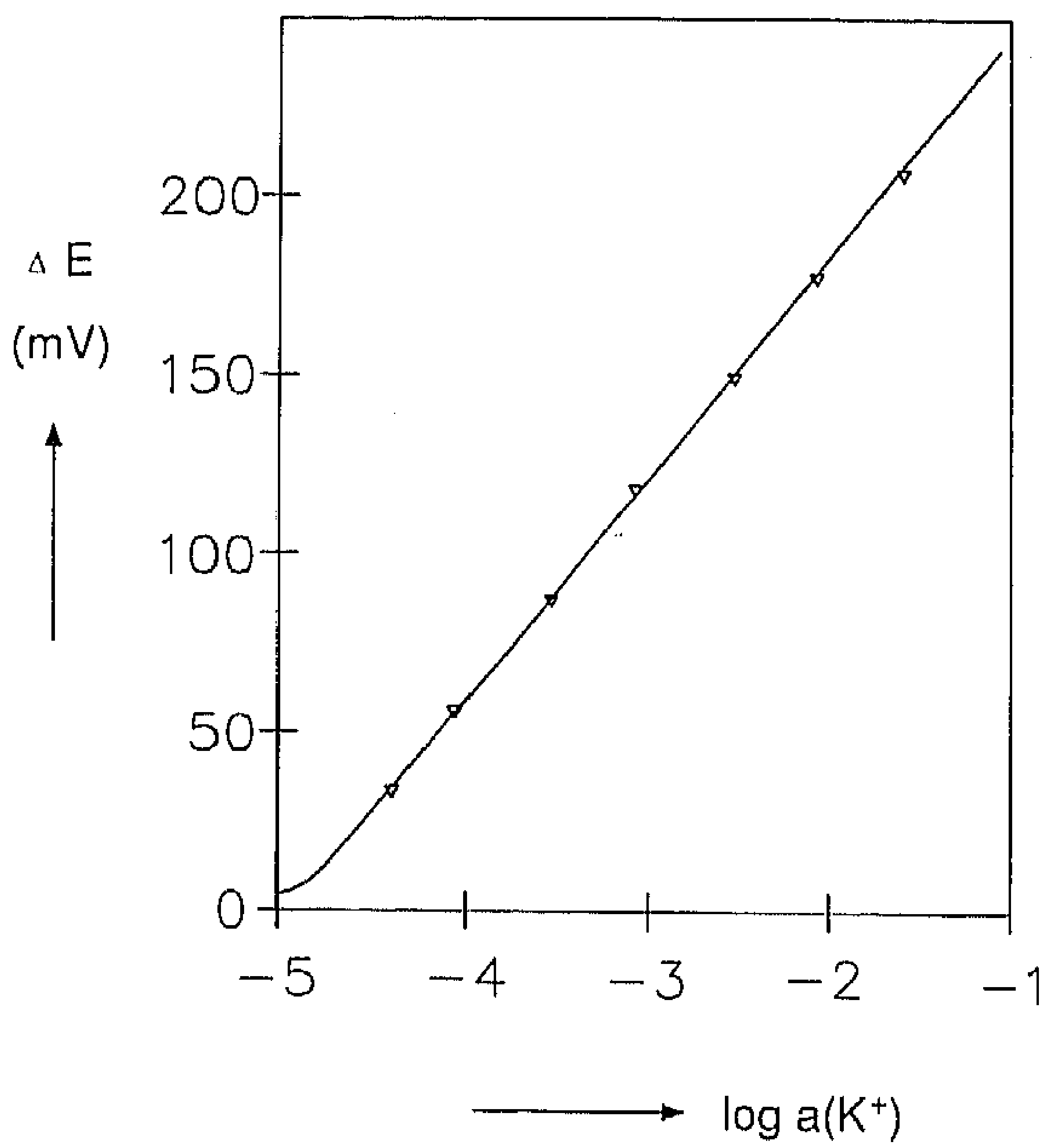

Fig, 3. Potassium ion response of ISFETs modified with Dow Corning 3140 RTV polysiloxane containing valinomycin in the presence of $0.1 \mathrm{M} \mathrm{NaCl}$.

carrier ISEs has been described [13-15]. It was observed that ISFETs modified with this material, containing valinomycin or hemispherand 3 or $\mathbf{4}$, give potassium-selective sensors with excellent performance (Table 2). For the synthetic ionophores only a minor deviation from linear response was observed at low potassium concentration (Fig. 4). The determined potentiometric selectivity coefficients are shown in Table 2.

\section{TABLE 2}

Performance of potassium-selective CHEMFETs using siloxane-based membranes

\begin{tabular}{llclc}
\hline $\begin{array}{l}\text { Membrane } \\
\text { material }\end{array}$ & $\begin{array}{l}\text { Iono- } \\
\text { phore } \\
(\text { wt.-\%) }\end{array}$ & $\begin{array}{l}\mathrm{KB}(\phi \mathrm{Cl})_{4} \\
(\mathrm{~mol}-\%)\end{array}$ & $\begin{array}{l}\text { Slope } \\
{[\mathrm{mV}} \\
\left.\left(\mathrm{pK}^{+}\right)^{-1}\right]\end{array}$ & $\begin{array}{l}\text { Selectivity } \\
\log K_{\mathrm{K}^{+}, \mathrm{Na}^{+}}\end{array}$ \\
\hline 3140 RTV & $\mathbf{1 ( 3 )}$ & - & 56 & $<-3.7$ \\
3140 RTV & $\mathbf{1 ( 3 )}$ & 67 & 56 & $<-3.7$ \\
Silopren & $\mathbf{1 ( 3 )}$ & - & 56 & $<-3.7$ \\
Silopren & $\mathbf{1 ( 3 )}$ & 67 & 55 & $<-3.7$ \\
Silopren & $\mathbf{3 ( 3 )}$ & - & 55 & $\leqslant-3.3$ \\
Silopren & $\mathbf{4 ( 3 )}$ & - & 56 & $\leqslant-3.1$ \\
\hline
\end{tabular}

"With respect to ionophore. ${ }^{\mathrm{b}}$ Fixed interference method, 0.10 $\mathrm{M} \mathrm{NaCl}$. 


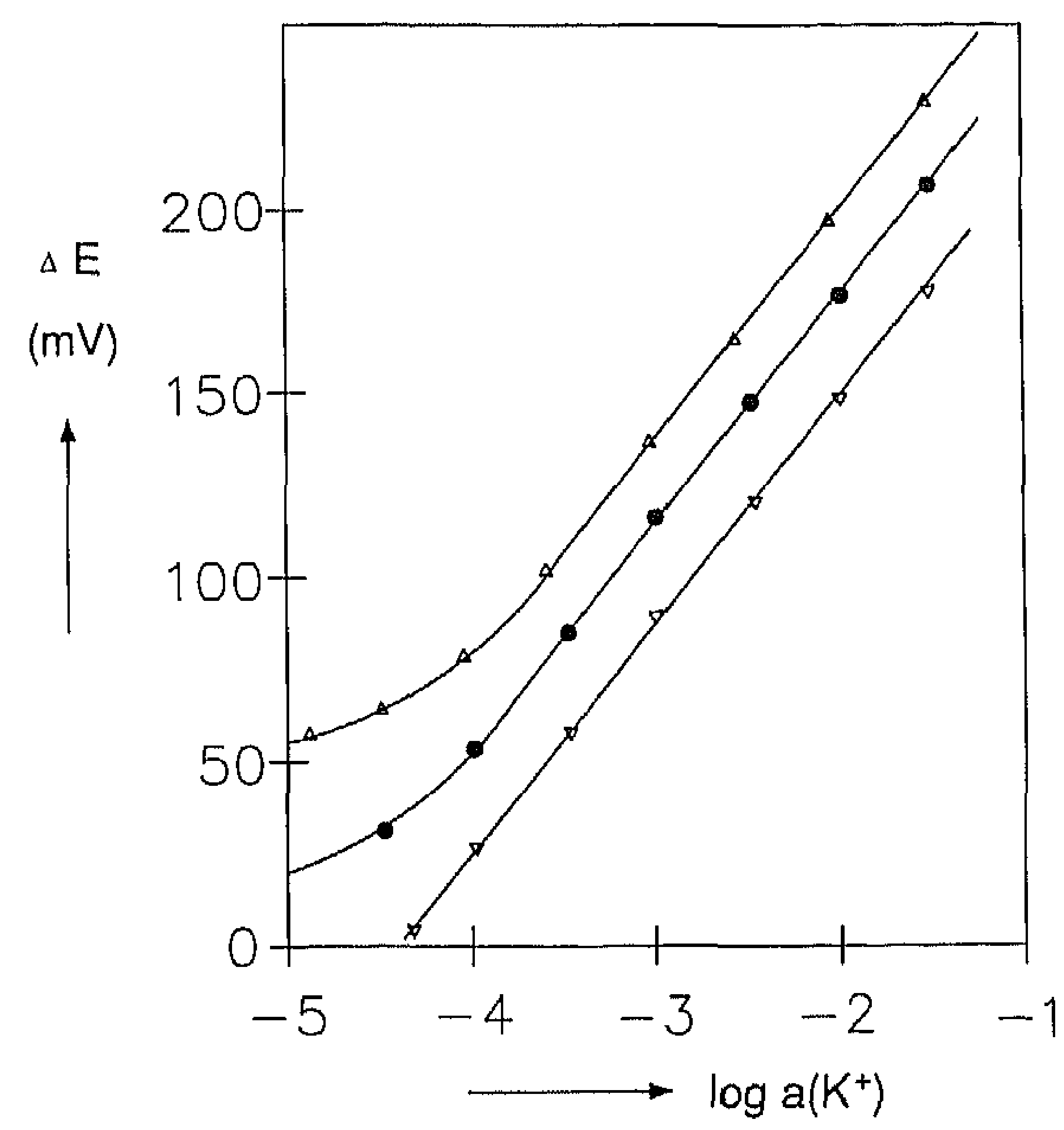

Fig. 4. Potassium ion response of ISFETs modified with Bayer Silopren containing $(\nabla)$ valinomycin $1,(\Delta)$ hemispherand 3 and (•) hemispherand 4 in the presence of $0.1 \mathrm{M} \mathrm{NaCl}$.

Continuous immersion of the modified ISFETs in the analyte solution for 8 weeks showed only a minor decrease in the slope to $54 \mathrm{mV}\left(\mathrm{pK}^{+}\right)^{-1}$. Also Silopren showed good adhesion to the ISFET surface, probably originating from bond formation between silanol groups on the gate oxide and the polysiloxane.

The eventual failure of CHEMFETs with these silicone rubber membranes is probably due to the leaching out of electroactive components, i.e., the ionophore and/or the anionic sites. Addition of $\mathrm{KB}(\phi \mathrm{Cl})_{4}$ to the 3140 RTV-valinomycin membrane system improved the durability drastically. From this observation it is concluded that the loss of anionic sites originating from impurities in the tested material is involved in the failure of this membrane system. As this effect was not observed for the Silopren membrane system, Silopren is assumed to contain intrinsic anionic sites. In the membranes containing valinomycin small crystallites were visible and the membranes with the synthetic ionophores were slightly cloudy, suggesting that the ionophore concentrations were above their solubility limit.

\section{Conclusions}

The acrylate membrane materials which have been successfully used in REFET membrane systems appear to be less applicable as CHEMFET membrane materials. The condensation-type RTV silicone rubbers can be used as alternatives to plasticized PVC in neutral carrier membrane materials. The use of these silicone rubbers has some advantages over plasticized PVC for this specific application: no plasticizer is used, so no leakage of this compound can occur, and the adhesion to the $\mathrm{SiO}_{2}$ surface is very good, probably owing to the formation of a chemical bond between the surface and the silicone rubber.

Silopren gave the best results of the silicone rubbers tested. The durability of CHEMFET's prepared from Silopren is at least 8 weeks. With the use of Silopren as the membrane matrix on a CHEMFET, part of the aims of the approach to solve the problems related to the CHEMFETs are fulfilled. Current research is focused on the synthesis of photopolymerizable siloxanes containing chemically bound ionophore and anionic sites, which can form in situ ion-selective membranes on the ISFET chips by using photolithographic techniques.

The Center of Microelectronics (CME) Twente is gratefully acknowledged for financial support.

\section{REFERENCES}

1 G.J. Moody, J.M. Slater and J.D.R. Thomas, Analyst, 113 (1988) 103.

2 G.F. Blackburn and J. Janata, J. Electrochem. Soc., 129 (1982) 2580 .

3 K. Bezegh, A. Bezegh, J. Janata, U. Oesch, A. Xu and W. Simon, Anal. Chem., 59 (1987) 2846.

4 T. Satchwill and J.D. Harrison, J. Electroanal, Chem., 202 (1986) 75 .

5 D.J. Harrison, A. Teclemariam and L.L. Cunningham, Transducers, (1987) 768.

6 G.J. Moody, B. Saad and J.D.R. Thomas, Analyst, 112 (1987) 1143.

7 R.W. Cattrall, P.J. Iles and I.C. Hamilton, Anal. Chim. Acta, 169 (1985) 403.

8 T.J. Cardwell, R.W. Caltrall, P.J. Iles and I.C. Hamilton, Anal. Chim. Acta, 170 (1985) 239.

9 T.J. Cardwell, R.W. Cattrall, P.J. Iles and 1.C. Hamilton, Anal. Chim. Acta, 204 (1988) 329. 
10 O.F. Schäfer, Anal. Chim. Acta, 87 (1976) 495.

11 U. Fiedler and J. Ruzicka, Anal. Chim. Acta, 67 (1973) 179.

12 S. Kawakami, T. Akiyama and Y. Ujihara, Fresenius' $Z$. Anal. Chem., 318 (1984) 349.

13 J. Pick, K. Tóth, E. Pungor, M. Vásak and W. Simon, Anal. Chim. Acta, 64 (1973) 477.

14 H.-B. Jenny, C. Riess, D. Amman, B. Magyar, R. Asper and W. Simon, Mikrochim. Acta, Part II, (1980) 309.

15 I.A. Mostert, P. Anker, H.-B. Jenny, U. Oesch, W.E. Morf, D. Arnman and W. Simon, Mikrochim. Acta, Part I, (1985) 33.

16 O.H. LeBlanc, Jr., and W.T. Grubb, Anal. Chem., 48 (1976) 1658.

17 J.F. Brown, Jr., G.M.J. Sluzarczuk and O.H. LeBlanc, Jr., U.S. Pat. 3743588, (1973).

18 M.L. Iglehart, R.P. Buck, G. Horvai and E. Pungor, Anal. Chem., 60 (1988) 1018.

19 G. Horvai, K. Tóth and E. Pungor, Anal. Chim. Acta, 216 (1989) 163.

20 R.D. Armstrong and M. Todd, J. Electroanal. Chem., 248 (1988) 131.

21 R.D. Armstrong, A.K. Covington and W.G. Proud, J. Electroanal. Chem., 257 (1988) 155.

22 A. van den Berg, P.D. van der Wal, M. SkowronskaPtasinska, E.J.R. Sudhölter, D.N, Reinhoudt and P. Bergveld, Anal. Chem. 59 (1987) 2827.

23 D.N. Reinhoudt, M.L.M. Pennings, and A.G. Talma, Eur. Pat. Appl., 85901604 (1985).
24 E.J.R. Sudhölter, A. van den Berg, M. SkowronskaPtasinska, P.D. van der Wal, D.N. Reinhoudt and P. Bergveld, in J.C. Lodder (Ed.), Sensors and Actuators, Kluwer, Deventer, 1986, p. 97.

25 A. van den Berg, P.D. van der Wal, M. SkowronskaPtasinska, E.J.R. Sudhölter, D.N. Reinhoudt and P. Bergveld, in Proceedings of the 2nd International meeting on Chemical Sensors, Bordeaux, 1986, p. 419.

26 E.J.R. Sudhölter, M. Skowronska-Ptasinska, P.D. van der Wal, A. van den Berg, and D.N. Reinhoudt, Sensors Actuators, 17 (1989) 189.

27 P.J. Dijkstra, H.J. den Hertog, Jr., B.J. van Steen, S. Zijlstra, M. Skowronska-Ptasinska, D.N. Reinhoudt, J. van Eerden and S. Harkema, J. Org. Chem., 2433 (1987) 52.

28 E.J.R. Sudhölter, P.D. van der Wal, M. SkowronskaPtasinska, A. van den Berg, P. Bergveld and D.N. Reinhoudt, Recl. Trav. Chim. Pays-Bas, (1990) in press.

29 E.J.R. Sudhölter, P.D. van der Wal, M. SkowronskaPtasinska, A. van den Berg, P. Bergveld and D.N, Reinhoudt, Anal. Chim. Acta, 230 (1990) 59.

30 E.J.R. Sudhölter, M. Skowronska-Ptasinska, P.D. van der Wal, A. van den Berg, and D.N. Reinhoudt, Eur. Pat. Appl., 258951 (1986).

31 M. Skowronska-Ptasinska, P.D. van der Wal, A. van den Berg, P. Bergveld, E.J.R. Sudhölter and D.N. Reinhoudt, Anal. Chim. Acta, 230 (1990) 67.

32 P. Bergveld, A. van den Berg, P.D. van der Wal, M. Skowronska-Ptasinska, E.J.R. Sudhölter and D.N. Reinhoudt, Sensors Actuators, 18 (1989) 309.

33 G.G. Guilbault and G. Nagy, Anal. Chem., 45 (1973) 417. 